\title{
Time to turn the page
}

$\mathrm{T}$ HIS NeW Year MARKS THE END OF MY FIFTH year as Editor-in-Chief of Cardiology in the Young. My career has taken me more into hospital management away from the clinical frontline of caring for children with heart disease. The time has come to hand over the editorship of the journal to those in the forefront of clinical care, of innovation, and of new discovery. I am pleased to say that my successor fulfils all these requirements. With the coming of 2014 , Jeff Jacobs, who has very ably supported me as an Associate Editor for the past 5 years, will take over as Editor-in-Chief. I am very grateful that Jeff has agreed to take on the role; it gives me great confidence in the future of the journal. With his succession, he will bring new Associate Editors and a new Editorial Board. This new team will refresh the journal and ensure it is fit for the future, both future of the science and understanding of children's cardiac disease and the future of scientific publishing.

Looking back over the 5 years I have been at the helm, I realise that the success of the journal has first and foremost been down to the authors of the many articles we have published over that time. I am enormously grateful to those of you who have entrusted your work to our pages. I hope we have done you justice. My apologies to those of you whose work we did not accept for publication; I hope you were nonetheless successful with you work and my thanks for the good grace with which most of you accepted our decision.

A journal such as ours is only as good as the quality of the articles it publishes, and deciding which of the many articles we receive should be published is not easy. The editor's job is only possible with the support and advice of expert reviewers. My heartfelt thanks to all of you who have provided me and the journal support by providing timely and authoritative reviews. Most of the papers we publish are greatly improved by the review process, and while the authors receive justifiable credit for their work the reviewers who have often made a considerable contribution to the finished work remain anonymous. I have been frequently overawed by the detailed work individual reviewers have undertaken in support of their authors and the wisdom of their advice to the editors.

I take particular pleasure in the truly international nature of our authorship and the extent to which we have expanded the origin of our published articles to one that is worldwide. I hope Cardiology in the Young will continue to publish articles addressing the challenges facing children and young people with heart disease and those caring for them from all parts of the world. The journal has also become more multi-disciplinary, not narrowly focused on medical cardiology but incorporating, surgical practice, nursing, psychology and more in addition. It has I hope reflected the full spectrum of the work of all professionals who have an interest in studying and improving the care of children with heart disease.

While there is much to celebrate about what we have published over the past 5 years in the journal, there are a few disappointments. I have in these pages before expressed concern that there are few clinical trials into the management of congenital heart disease. ${ }^{1}$ Most of the articles we publish are observational studies, of value certainly, but not the first rank of clinical evidence. We owe to the children we care for to make sure that the best evidence guides their treatment. Can we yet say we have achieved this?

I have also written about the importance of configuring our clinical services so that they deliver the best outcomes for our patients. ${ }^{2}$ There is much evidence to support how services should be provided and the volume of work is necessary to provide the expertise and experience to achieve the best care, yet this has largely been ignored. Surely the time has come for us to examine the evidenced carefully and come to a professional consensus of how best to organise how we provide care. In the absence of such a consensus, opportunities will be lost, as they have been in the debate here in England over the past 3 years that has generated so much heat and made so little progress.

One more topic about which I would like to have published more is patient safety. The care we provide is highly technical and inevitably caries risk. 
It is imperative that we do all we can to reduce this risk to a minimum. It is now well recognised in medicine that the reliability and reproducibility of clinical processes are critical to providing safe care. ${ }^{3,4}$ Despite this, there is relatively little work in this area in children's cardiac care and Cardiology in the Young has not been able to publish to any great extent on the topic. This is certainly a disappointment, but as I have said disappointments are few. The journal has much to celebrate and as I pass the stewardship of it to a new leadership, there remains, as there always will, untapped opportunities to explore. As Cardiology in the Young turns a new page and enters a new era, there is much to anticipate.

Edward Baker Editor-in-Chief

\section{References}

1. Baker E. Trials and tribulations. Cardiol Young 2003; 13: 395-396.

2. Baker E. The greatest good to the greatest number. Cardiol Young 2002; 12: 209-210.

3. Baker E. Quality is measured by more than the clinical outcome. Cardiol Young 2008; 18: 449-450.

4. Lindberg HL. Pediatric cardiac surgery and safety, in the past and in the future. Prog Pediatr Cardiol 2012; 33: 11-13. 